\title{
Causes of misdiagnoses by thyroid fine- needle aspiration cytology (FNAC): our experience and a systematic review
}

\author{
Yanli Zhu', Yuntao Song ${ }^{2}$, Guohui $\mathrm{Xu}^{2}$, Zhihui Fan ${ }^{3}$ and Wenhao Ren ${ }^{*}$
}

\begin{abstract}
Objective: FNA is a simple, safe, cost-effective and accurate diagnostic tool for the initial screening of patients with thyroid nodules. The aims of this study were to determine the diagnostic utility of FNAC performed in our institution, assess the cytomorphologic features that contribute to diagnostic errors and propose improvement measures.

Methods: A total of 2781 FNACs were included in the study, and 1122 cases were compared with their histological diagnoses. We retrospectively reexamined our discordant (both false-negative and false-positive) cases and performed a systematic review of previous studies on causes of misdiagnoses.

Results: When DC V and DC VI were both considered cytologic-positive, the sensitivity, specificity, positive predictive value (PPV), negative predictive value (NPV) and diagnostic accuracy were 98.3, 30.9, 94.9, 58.3 and 93.5\%, respectively. If DC VI was considered cytologic-positive, the sensitivity, specificity, PPV, NPV and diagnostic accuracy of FNAC were 98.0, 84.0, 99.4, 58.3, and 97.5\% respectively. The main cause of false-negative diagnoses was sampling error $(13 / 15,86.7 \%)$, while interpretation error led to the majority of the false-positive diagnoses (38/47, 80.9\%). Overlapping cytological features in adenomatous hyperplasia, thyroiditis and cystic lesions were the major factors contributing to interpretation errors, while the size and number of nodules may have led to false-negative diagnoses because of heterogeneity and unsampled areas.

Conclusions: The sensitivity and PPV of thyroid FNAC in our institution were higher than those in the published data, while the specificity and NPV were lower. Regarding the FNA category DC V, a frozen section analysis during diagnostic lobectomy is necessary. Multiple passes should be performed in various parts of a large nodule or from different nodules to reduce the risk of false-negative findings. Cytopathologists should strengthen their criteria for the identification of adenomatous hyperplasia, thyroiditis and cystic lesions to avoid false-positive diagnoses. NIFTP has little effect on diagnostic accuracy and the distribution of diagnostic errors.
\end{abstract}

Keywords: Thyroid, Fine-needle aspiration cytology (FNAC), False-negative, False-positive, Noninvasive follicular thyroid neoplasm with papillary-like nuclear features (NIFTP)

\footnotetext{
* Correspondence: 295723446@qq.com

${ }^{1}$ Key laboratory of Carcinogenesis and Translational Research (Ministry of Education), Department of Pathology, Peking University Cancer Hospital and Institute, Beijing 100142, China

Full list of author information is available at the end of the article
}

(c) The Author(s). 2020 Open Access This article is distributed under the terms of the Creative Commons Attribution 4.0 International License (http://creativecommons.org/licenses/by/4.0/), which permits unrestricted use, distribution, and reproduction in any medium, provided you give appropriate credit to the original author(s) and the source, provide a link to the Creative Commons license, and indicate if changes were made. The Creative Commons Public Domain Dedication waiver (http://creativecommons.org/publicdomain/zero/1.0/) applies to the data made available in this article, unless otherwise stated. 


\section{Introduction}

Thyroid nodules are common; most nodules are benign, and approximately $5 \%$ of excised nodules are malignant [1]. The main goal of thyroid fine-needle aspiration (FNA) is to identify the nodules that require surgery and decrease the overall incidence of thyroidectomy among patients with benign disease. Fine-needle aspiration cytology (FNAC) is an efficient and reliable means for the evaluation of thyroid nodules and is considered the gold standard for preoperative diagnoses [2-4]. At the same time, FNA of thyroid nodules has limitations in that both false-negative and false-positive results can occur $[5,6]$.

The current study was undertaken to determine the diagnostic utility of FNAC performed in our institution by correlating FNAC results with histological diagnoses. We aimed to retrospectively re-examine our discordant (both false-negative and false-positive) cases, to perform a systematic review of previous studies to assess the cytomorphologic features that contributed to diagnostic errors and to propose improvement measures.

Moreover, the new pathologic entity "noninvasive follicular thyroid neoplasm with papillary-like nuclear features" (NIFTP) has been introduced, but whether this procedure will affect the distribution of diagnostic errors remains uncertain.

\section{Materials and methods Thyroid FNA cases}

Patients who underwent preoperative thyroid FNA between April 2014 and March 2019 at Peking University Cancer Hospital were identified, and their FNA results were compared with surgical pathology findings. The data were retrieved from the electronic medical records. FNAs were performed by surgeons or sonographers either by palpation or via ultrasound guidance without onsite evaluation. The aspirates were prepared as direct smears (hematoxylin-eosin stain) and/or liquid-based cytology (Papanicolaou stain). All cases were initially classified according to the recommended six diagnostic categories (DCs) of the Bethesda system for reporting thyroid cytopathology (TBSRTC), including nondiagnostic or unsatisfactory (ND/UNS; I); benign (B; II); atypia of undetermined significance or follicular lesion of undetermined significance (AUS/FLUS; III); suspicious for follicular neoplasm or follicular neoplasm (SFN/FN; IV); suspicious for malignancy (SM; V); and malignant (M; $\mathrm{VI}$ ). Adequacy was determined on the basis of the standard Bethesda criteria [7].

\section{The false-negative and false-positive diagnoses}

When both DC V and DC VI were considered cytologicpositive (both need surgical excision according to the American Thyroid Association guidelines) [8] and when
DC II was considered cytologic-negative, a false-negative diagnosis was defined as a nodule that was benign by FNAC (DC II of TBSRTC) and malignant by final histological examination, and a false-positive diagnosis was defined as a nodule with malignant cytology (DC V and DC VI) and postsurgical histological findings of a nonneoplastic lesion or benign neoplasm.

When indeterminant and nondiagnostic cytological findings were not present, DC VI was considered cytologic-positive, and DC II was considered cytologicnegative, a false-negative diagnosis was defined as a nodule that was benign by FNAC (category II of TBSRTC) and malignant by final histological examination, and a false-positive diagnosis was defined as a case that was positive for DC VI by FNA and had postsurgical histological findings of a nonneoplastic lesion or benign neoplasm.

We divided the misdiagnoses into two categories: 'specimen problem', including sampling error (tumor cells were not aspirated) or a suboptimal specimen ('scant but adequate sampling' or 'preparation artifact'), and 'interpretation error', meaning there were overdiagnoses or underdiagnoses by cytologists. All of the slides from the false-negative and false-positive FNAs were reexamined, and it was determined whether the misdiagnoses were due to a specimen problem or interpretation error.

\section{Statistical analysis}

For "NIFTP $=\mathrm{Ca}$ " and "NIFTP $\neq \mathrm{Ca}$ ", the sensitivity, specificity, positive predictive value (PPV), negative predictive value (NPV) and diagnostic accuracy were assessed.

Statistical analysis was performed using IBM SPSS Statistics (version 20.0). The variables were mainly categorical, and the chi-square test was used. A $P$ value was considered significant when less than 0.05 .

\section{Results \\ Patients}

Between April 2014 and March 2019, a total of 2781 thyroid FNACs were reviewed in our institution. Of the 2781 patients, 2109 were female $(75.8 \%)$, and 672 were male $(24.2 \%)$. The age range was $15-89$ years. For the total 2781 FNACs, the incidences of the six diagnostic categories (I-VI) were as follows: 14.8, 17.1, 15.8, 2.3, 11.6 , and $38.5 \%$, respectively.

\section{Postsurgery histological findings of follow-up cases}

In the entire study population, 1122 cases had available histological correlation data, of which 132 cases (11.8\%) had nonneoplastic lesions, 17 cases (1.5\%) had benign neoplasms, 969 cases $(86.4 \%)$ had malignant neoplasms, and 4 cases $(0.4 \%)$ had NIFTP. The FNA results were compared with the corresponding histological diagnoses (Table 1). 
Table 1 The distribution of the cytologic-histologic correlation of the nodules

\begin{tabular}{|c|c|c|c|c|c|c|c|c|c|c|}
\hline \multirow[t]{3}{*}{ DC } & \multirow[t]{3}{*}{ Cases } & \multirow{3}{*}{$\begin{array}{l}\text { non- } \\
\text { neoplastic } \\
\text { lesions }\end{array}$} & \multicolumn{8}{|c|}{ Neoplastic lesions } \\
\hline & & & \multirow{2}{*}{$\begin{array}{l}\text { Benign } \\
\text { neoplasms }\end{array}$} & \multirow[t]{2}{*}{ NIFTP } & \multicolumn{6}{|c|}{ Malignant neoplasms } \\
\hline & & & & & Total & PTC & MTC & FTC & ATC & ITTA \\
\hline I & $42(10.2 \%)$ & 17 & 0 & 1 & 24 & 24 & & & & \\
\hline$\|$ & $36(7.6 \%)$ & 20 & 1 & 1 & 14 & 14 & & & 0 & \\
\hline III & $90(20.5 \%)$ & 39 & 6 & & 45 & 43 & 2 & & & \\
\hline IV & $29(45.3 \%)$ & 12 & 7 & 1 & 9 & 8 & & 1 & & \\
\hline V & $200(62.7 \%)$ & 41 & 2 & & 157 & 149 & 7 & 1 & & \\
\hline $\mathrm{Vl}$ & 725 (67.6\%) & 3 & 1 & 1 & 720 & 710 & 7 & & 2 & 1 \\
\hline Total & 1122 (40.3\%) & 132 & 17 & 4 & 969 & 948 & 16 & 2 & 2 & 1 \\
\hline
\end{tabular}

DC Diagnostic category, NIFTP Non-invasive follicular thyroid neoplasm with papillary-like nuclear features, PTC Papillary thyroid carcinoma, MTC Medullary thyroid carcinoma, FTC Follicular thyroid carcinoma, ATC Anaplastic thyroid carcinoma, ITTA Intrathyroidal thymic adenocarcinoma

\section{The diagnostic utility of TBSRTC}

For "NIFTP=Ca", when DC V and DC VI both indicated positive findings (both need surgical excision according to the American Thyroid Association guidelines [8]), the sensitivity, specificity, PPV, NPV and diagnostic accuracy were 98.3, 30.9, 94.9, 58.3 and 93.5\%, respectively. If DC VI was considered cytologicpositive, the sensitivity, specificity, PPV, NPV, and diagnostic accuracy of FNAC were 98.0, 84.0, 99.4, 58.3, and $97.5 \%$, respectively.

For "NIFTP $\neq \mathrm{Ca}$ ", when DC V and DC VI were both considered positive findings, the sensitivity, specificity, PPV, NPV and diagnostic accuracy were 98.4, 31.4, 94.8, 61.1 and $93.5 \%$, respectively. If DC VI was considered cytologic-positive, the sensitivity, specificity, PPV, NPV and diagnostic accuracy were 98.1, 81.5, 99.3, 61.1, and $97.5 \%$, respectively.

NIFTP does not affect diagnostic accuracy or notably influence the distribution of diagnostic errors.

\section{Analysis of the misdiagnosed cases}

When DC V and DC VI were both considered cytologicpositive, there were 62 misdiagnosed cases, including 15 false-negative and 47 false-positive cases. However, if DC VI was considered cytologic-positive, there were only 19 misdiagnosed cases, including 15 false-negative and 4 false-positive cases.

We performed a retrospective review of the 62 falsenegative and false-positive cases and found that 23 (38.1\%) cases were due to specimen problem and 39 (61.9\%) cases resulted from interpretation error. The 23 cases with specimen problems comprised 13 sampling errors and 10 suboptimal specimens. The main cause of the false-negative diagnoses was sampling error (13/15, $86.7 \%$ ), while interpretation error led to most of the false-positive diagnoses (38/47, 80.9\%). The analysis of the misdiagnosed cases is shown in Table 2.

\section{Analysis of the false-negative cases}

In a review of the 14 false-negative cases resulting from specimen problems, the findings demonstrated that the following factors may have contributed: papillary thyroid microcarcinoma (PTMC) $(n=6)$; thyroid cancer in patients with multinodular goiter $(n=4)$; diffuse fibrosis $(n=2)$; and nonspecific factors $(n=2)$.

Only one false-negative diagnosis was due to interpretation error; the postoperative histopathologic diagnosis of this case was follicular variant of papillary thyroid carcinomas (FVPTC), while cytopathologic evaluation result indicated a benign tumor. The analysis of the falsenegative cases is presented in Table 3.

\section{Analysis of the false-positive cases}

When DC V and DC VI were both considered cytologicpositive, 47 of our patients had false-positive diagnoses. Thirty-eight (80.9\%) false-positive diagnoses were due to interpretation errors, and the postoperative histopathologic diagnoses of these cases were benign lesions with features mimicking or suggestive of a neoplasm including adenomatous hyperplasia $(n=17)$, thyroiditis $(n=$ $12)$, and cystic lesions $(n=9)$. A suboptimal specimen is the second most common contributor to the falsepositive rate. In this study, our data showed that six cases of thyroiditis, two cases of goiter with diffuse fibrosis and one case of PTMC were all misdiagnosed as PTC due to overlapping cytological features. The analysis of the false-positive cases is presented in Table 4.

Regarding positive findings for $\mathrm{DC} \mathrm{VI}$, there were a total of 4 false-positive diagnoses, including adenomatous hyperplasia $(n=2)$ and cystic lesions $(n=2)$.

\section{Discussion}

\section{The diagnostic utility of TBSRTC}

FNA is a simple, safe, cost-effective and accurate diagnostic tool for the initial screening of patients with 
Table $\mathbf{2}$ The analysis for the misdiagnostic cases

\begin{tabular}{lclll}
\hline & Specimen problem & & Interpretation \\
\cline { 2 - 4 } & Sampling error & Suboptional specimen & 1 & Total \\
\hline False-negative diagnoses & 13 & 1 & 38 & 15 \\
False-positive diagnoses & 0 & 9 & 39 & 47 \\
Total & 23 & & 62 \\
\hline
\end{tabular}

thyroid nodules [8-10]. The aim of FNA is to identify neoplastic nodules for surgical removal while avoiding surgical intervention for nonneoplastic lesions. In our study, when DC V and DC VI were both considered cytologic-positive, the sensitivity, specificity, PPV, NPV and diagnostic accuracy were 98.3, 30.9, 94.9, 58.3 and 93.5\%, respectively. If DC VI was considered cytologicpositive, the sensitivity, specificity, PPV, NPV and diagnostic accuracy of FNAC were 98.0, 84.0, 99.4, 58.3, and $97.5 \%$. Therefore, a key point of our study is that DC V is not highly reliable for the diagnosis of malignancy, and when excluding this category, the diagnostic accuracy and especially the specificity, increase. Therefore, for cytological diagnoses of $\mathrm{DC} \mathrm{V}$, a frozen section analysis during diagnostic lobectomy is necessary. The PPV and diagnostic accuracy all exceeded $90.0 \%$, indicating that thyroid FNA is an important part of the preoperative diagnosis.

It is well known that thyroid FNA derives much of its clinical value from its ability to reliably enable the identification of benign thyroid nodules and its low falsenegative rate, which enables surgeons to use FNA as a reliable test for guiding operative decision-making; thus, the lower the false-negative rate is, the more valuable thyroid FNA will be. Each category of the TBSRTC has an implied cancer risk, which ranges from 0 to $3 \%$ for the "benign" category to virtually $100 \%$ for the "malignant" category [7]. The false-negative rates of FNA for thyroid nodules reported by most studies are less than $5 \%$ [11-16]. However, higher rates (varying from 7.5 to $21 \%)$ have also been published in other study series [17-

Table 3 The analysis for the false-negative cases

\begin{tabular}{ll}
\hline Analysis & Number \\
\hline Specimen problem & 6 \\
PTMC & 2 \\
Diffuse fibrosis & 4 \\
Thyroid cancer in patients with multinodular goiter & 2 \\
Nonspecific factors &
\end{tabular}

Interpretation error

\begin{tabular}{lc} 
FVPTC & 1 \\
Total & 15 \\
\hline $\begin{array}{l}\text { PTMC Papillary thyroid microcarcinoma, FVPTC follicular variant of papillary } \\
\text { thyroid carcinomas }\end{array}$
\end{tabular}

$22]$. In the present study, the false-negative rate (1.7\%) was lower than those of reported studies, demonstrating that our negative thyroid FNA results were fairly reliable. However, the relatively low NPV (58.3\%) showed that despite a thyroid nodule being initially diagnosed as benign by FNA, it may have malignant potential. Moreover, it is noteworthy that the categorization of cases at DC I or DC II does not mean "negative for malignancy", and these patients should undergo regular, close followup or diagnostic lobectomy if the clinician thinks it is possible that the tumor is malignant. We acknowledge that the NPV data are more informative because most cytologically benign thyroid nodules do not require surgery.

\section{Analysis of the false-negative cases}

In our study, most false-negative diagnoses were caused by specimen problems $(87.5 \%, 14 / 16)$, and 6 of 14 cases had PTMC with a resultant sampling of adjacent normal tissue. Papillary thyroid microcarcinoma (PTMC) is defined by the World Health Organization (WHO) as a PTC whose longest diameter measures $\leq 1.0 \mathrm{~cm}$ and that is found incidentally [23]. As previous studies had noted, PTCs measuring less than $1 \mathrm{~cm}$ in diameter are usually incidental and discounted as false-negative by some pathologists [24-27]. In fact, in some studies, the most common cause of a false-negative diagnosis by FNA is the presence of an unsampled microcarcinoma in the setting of an adenomatous goiter [15, 28]. Notably, thyroids with large nodules may harbor microcarcinomas within the nodule; moreover, once a nodule reaches a

Table 4 The analysis for the false-positive cases

\begin{tabular}{ll}
\hline Analysis & Number \\
\hline Suboptional specimen & 6 \\
Thyroiditis & 2 \\
Goiter with diffuse fibrosis & 1 \\
PTMC & \\
& \\
Cystic lesions & 9 \\
Thyroiditis & 12 \\
Adenomatous hyperplasia & 17 \\
Total & 47 \\
\hline PTMC Papillary thyroid microcarcinoma &
\end{tabular}

PTMC Papillary thyroid microcarcinoma 
certain size, it may be difficult to precisely sample the entire nodule [29], and an increased false-negative rate for larger nodules has been reported by some authors [27, 30-33]. Several researchers have reported falsenegative rates as high as 17 to $19.3 \%$ for thyroid nodules $\geq 3$ to $4 \mathrm{~cm}[19,20]$. However, this concept had been challenged by other reports showing that a large nodule size neither diminishes the accuracy of FNA nor increases the risk of malignancy within the aspirated nodule $[34,35]$. We support the former viewpoint for the following two reasons: first, nodule heterogeneity has been revealed to be one of the underlying causes of misdiagnoses, which may explain the difficulties in evaluating these nodules by traditional cytologic methods [32], and second, it should be noted that the number of patients undergoing surgery in the latter series with the opposing view ( $n=145$ and $n=127$ ) may not have been sufficient to demonstrate the significant effect of nodule size, even if one existed.

Another factor of great concern regarding falsenegative diagnoses is the number of nodules, and sampling error may occur when the cells captured by the needle are not from the targeted nodule. On the basis of reviewing the 4 false-negative cases with multiple nodules in our study, we found that a benign nodule was located preoperatively, while the hidden nodule in the tumor was missed. Studies have demonstrated the high incidence of malignancy in patients with multinodular goiter compared to the general population [36] and that the presence of multiple nodules can hamper the evaluation of the entire thyroid [37]. Therefore, false-negative results may arise due to heterogeneity within the targeted nodule or among diverse nodules, so multiple passes should be performed in various parts of a large nodule or from different nodules to reduce the risk of false-negative findings owing to heterogeneity.

Our data suggest that interpretation error was not the major cause of false-negative diagnoses $(n=1)$. We found only one case of a FVPTC that was classified as benign by cytopathologic evaluation. Previous authors have also noted FVPTC to be an important factor in false-negative thyroid FNA results, and the value of thyroid FNA is limited by its inability to distinguish follicular lesions reliably [16, 38-41]. Histopathologic features of FVPTC tend to overlap with those of follicular neoplasms, hyperplastic adenomatoid nodules in goiter or even lymphocytic thyroiditis, as the characteristic nuclear features often present with subtle nuclear changes. In addition, nodule heterogeneity is also a particular problem with FNA of FVPTC, whose histological diagnoses of malignancy may be made in accordance with nuclear features of PTC while the features present only focally in the nodule. As a result, this tumor is frequently misinterpreted as a follicular neoplasm or an adenomatoid nodule. We acknowledge that for these follicular lesions, cytopathology is a screening tool rather than a diagnostic test and that the main goal of cytopathology is not to establish an absolute diagnosis but to determine the correct management for the patient. Sule Canberk et al. [6] have also emphasized that remembering three "As" could prevent misinterpretations and enable better clinical management: be aware of the limits of cytomorphology; be awake to the presence of sheets/ macrofollicles, abundant colloid, lymphocytes, and obscuring blood; and avoid down-grading nuclear atypia.

\section{Analysis of the false-positive cases}

The 47 thyroid FNACs with a histopathology-proven false-positive diagnosis demonstrated that the following were the major contributing factors to false-positive cytologic diagnoses: adenomatous hyperplasia, thyroiditis and cystic lesions.

Our data suggested that hyperplastic and adenomatoid nodules represented the most significant pitfall in thyroid FNAs, in which these types of pathology can be misinterpreted as suspicious for PTC or PTC. Benign thyroid hyperplastic nodules typically show follicular epithelial cells with small, round, dark nuclei in a honeycomb arrangement. However, focal nuclear atypia that can be mistaken for PTC, including grooves, an oval shape, chromatin clearing, and overlapping, have been reported in hyperplastic nodules, which leads to diagnostic difficulties [42, 43]. It is worth mentioning that benign thyroid nodules with papillary hyperplasia can pose a diagnostic challenge not only in cytology but also in surgical pathology by mimicking classical PTC [44-47]. Marc P et al. [42] have underscored that benign thyroid nodules with papillary hyperplasia should be considered when a FNA reveals papillary structures with sparse nuclear features of PTC or features that are mixed with an otherwise benign-appearing follicular component. Other researchers have stressed that nuclear overlapping and crowding is a rare finding in specimens of benign thyroid hyperplasia and that the presence of abundant loose or watery colloid can prevent overdiagnoses by cytopathologists $[48,49]$.

Previous studies have demonstrated that thyroiditis is one of the most common factors in the false-positive diagnosis of PTC $[28,43,50-52]$. We believe that the serious overlap in morphological features between PTC in chronic lymphocytic thyroiditis and pure thyroiditis can pose a challenge for the cytopathologist, and even an experienced cytopathologist may be uncertain about the diagnosis between these two entities. In our experience, 18 of the 47 false-positive cases were thyroiditis, including 9 cases of granulomatous thyroiditis and 4 cases of Hashimoto's thyroiditis. Diagnostic traps in the 
cytological evaluation of thyroiditis vary depending on the stage of the disease. The 'cellular stage' is composed of a proliferation of oncocytes, and an oncocytic change may lead to some nuclear atypia: nuclear enlargement, fine chromatin texture, prominent nuclear membranes and macronucleoli. Occasional nuclear grooves or pseudoinclusions and a paucity of background lymphocytes can lead to overdiagnoses of PTC. In contrast, the 'fibrotic stage' is widely fibrotic, and sclerosing and may yield few cells upon FNA. However, squamous metaplasia of thyroid follicular epithelial cells may be misinterpreted as suspicious for malignancy. In such cases, scanty cellularity can be considered worrisome in the case of the presence of some atypical cells suggesting PTC $[6,53,54]$. There are some key diagnostic clues that can help distinguish between reactive nuclear changes and PTC in chronic lymphocytic thyroiditis. The reactive follicular epithelium in chronic lymphocytic thyroiditis is usually adjacent to the inflammatory infiltrate and with focal nuclear atypia showing some but not all features of PTC $[53,55]$. Identifying the multinucleated giant cells, epithelioid histiocytes, and fibrotic stromal fragments in the complex background created by acute-chronic inflammation and debris can improve the sensitivity for the diagnosis of granulomatous thyroiditis [56-58]. However, it should be noted that the presence of multinucleated giant cells does not rule out the diagnosis of thyroid cancer. The diagnosis of granuloma must be based on careful observation of all sections and the absence of thyroid cancer cells.

In evaluations of cystic nodules, the role of FNAC is limited, and false-negative diagnoses of malignant cysts are well documented [20,59-63]. However, only a few authors have emphasized that atypical cyst-lining cells may produce false-positive cytologic results, and few have fully demonstrated the cytologic and histologic features of atypical cyst-lining cells [5, 61]. Our study found that 9 cases of benign cystic lesions were misdiagnosed as suspicious for PTC, and we retrospectively scrutinized the smears. Consistent with the opinion of Faquin et al. [61], the "atypical" cells demonstrated a cytomorphologic spectrum from spindle, elongated cells to polygonal, epithelioid cells with nuclear enlargement, nuclear grooves, fine chromatin, and distinct nucleoli while lacking nuclear crowding, such as intranuclear pseudoinclusions, and the papillary architecture of cystic papillary carcinomas. Malheiros et al. [5] have also emphasized that if atypical features are seen in smears from those cystic lesions with a paucicellular background, the diagnosis of PTC should be made with great caution only if we find unequivocally nuclear features of PTC. Accordingly, we recommend that accurate identification of atypical cyst-lining cells and their background is crucial to distinguish the benign nature of cystic thyroid nodules and avoid unnecessary operations.
Intraoperative frozen examination in misdiagnosed cases For DC I, DC II and indeterminant cytologic diagnoses, if the clinician still suspects malignancy, intraoperative frozen examination is helpful to determine the nature and scope of the operation. At our institution, 54 of the 62 misdiagnosed cases had frozen sections; among those cases, $11(20.4 \%)$ had inconclusive frozen section results. It is important to note that among the false-positive cases, 5 cases were suspicious for PTC, and one case was diagnosed as PTC based on the frozen section analysis. Massimo et al. [64] explained that there are two main limitations for frozen section analysis. First, the quality of the specimen obtained for a frozen section is lower than that obtained during routine histopathological examination. Second, the single frozen section obtained may not be representative of the lesion as a whole. Thus, we must acknowledge that it is difficult to achieve an accurate diagnosis by FNAC for some cases.

\section{Conclusions}

The sensitivity and PPV of thyroid FNAC in our institution were higher than those of other institutions, while the specificity and NPV were lower. Specimen problems were the main causes of false-negative diagnoses, while interpretation error led to most of the false-positive diagnoses. Multiple passes should be performed in various parts of a large nodule or in different nodules to reduce the false-negative rate due to specimen problems. Cytopathologists should strengthen their criteria for the identification of adenomatous hyperplasia, thyroiditis and cystic lesions to avoid false-positive diagnoses due to interpretation errors. NIFTP does not affect the diagnostic accuracy or notable influence the distribution of diagnostic errors.

\section{Abbreviations}

AUS/FLUS: Atypia of undetermined significance or follicular lesion of undetermined significance; DC: Diagnostic categories; FNA: Fine-needle aspiration; FNAC: Thyroid fine-needle aspiration cytology; ND/

UNS: Nondiagnostic or Unsatisfactory; NIFTP: Non-invasive follicular thyroid neoplasm with papillary-like nuclear features; NPV: Negative predictive value; PPV: Positive predictive value; PTC: Papillary thyroid carcinoma;

PTMC: Papillary thyroid microcarcinoma; SFN/FN: Suspicious for follicular neoplasm or Follicular neoplasm; SM: Suspicious for malignancy; TBSRTC: The Bethesda System for Reporting Thyroid Cytology

\section{Acknowledgements}

Not applicable.

\section{Authors' contributions}

Yan-li Zhu initiated the study and wrote the manuscript. Wen-hao Ren collected all data and revised the manuscript. Yan-li Zhu and Wen-hao Ren reviewed all slides. Yuntao Song and Guohui Xu performed the fine needle aspiration as the surgeons, Zhihui Fan performed the fine needle aspiration as a sonographer. All authors have read and approved the final version of the manuscript.

Funding

Not applicable. 


\section{Availability of data and materials}

The datasets used and/or analyzed during the current study are available from the corresponding author on reasonable request.

\section{Ethics approval and consent to participate}

All patient samples and clinical data using were approved by the Ethics committee of the Peking University Cancer Hospital and the exemption from informed consent was approved as well.

\section{Consent for publication}

Not applicable.

\section{Competing interests}

The authors declare that they have no competing interest.

\begin{abstract}
Author details
'Key laboratory of Carcinogenesis and Translational Research (Ministry of Education), Department of Pathology, Peking University Cancer Hospital and Institute, Beijing 100142, China. ${ }^{2}$ Key laboratory of Carcinogenesis and Translational Research (Ministry of Education), Department of Head and Neck Surgery, Peking University Cancer Hospital and Institute, Beijing 100142, China. ${ }^{3}$ Key laboratory of Carcinogenesis and Translational Research (Ministry of Education), Department of Ultrasound, Peking University Cancer Hospital and Institute, Beijing 100142, China.
\end{abstract}

\section{Received: 25 September 2019 Accepted: 27 December 2019}

\section{Published online: 03 January 2020}

\section{References}

1. Hegedus L, Bonnema SJ, Bennedbaek FN. Management of simple nodular goiter: current status and future perspectives. Endocr Rev. 2003;24(1):10232.

2. Tamhane S, Gharib H. Thyroid nodule update on diagnosis and management. Clin Diabetes Endocrinol. 2016;2:17.

3. Cramer H. Fine-needle aspiration cytology of the thyroid: an appraisal. Cancer. 2000;90(6):325-9.

4. Sheffield BS, Masoudi H, Walker B, Wiseman SM. Preoperative diagnosis of thyroid nodules using the Bethesda system for reporting thyroid cytopathology: a comprehensive review and meta-analysis. Expert Rev Endocrinol Metab. 2014:9(2):97-110.

5. Malheiros DC, Canberk S, Poller DN, Schmitt F. Thyroid FNAC: Causes of false-positive results. Cytopathology. 2018;29(5):407-17.

6. Canberk S, Firat P, Schmitt F. Pitfalls in the cytological assessment of thyroid nodules. Turk Patoloji Derg. 2015;31(Suppl 1):18-33.

7. Cibas ES, Ali SZ. The 2017 Bethesda system for reporting thyroid cytopathology. Thyroid. 2017;27(11):1341-6.

8. Haugen BR, Alexander EK, Bible KC, Doherty GM, Mandel SJ, Nikiforov YE, et al. 2015 American Thyroid Association management guidelines for adult patients with thyroid nodules and differentiated thyroid Cancer: the American Thyroid Association guidelines task force on thyroid nodules and differentiated thyroid Cancer. Thyroid. 2016;26(1):1-133 20,34,51.

9. Danese D, Sciacchitano S, Farsetti A, Andreoli M, Pontecorvi A. Diagnostic accuracy of conventional versus sonography-guided fine-needle aspiration biopsy of thyroid nodules. Thyroid. 1998;8(1):15-21.

10. Carmeci C, Jeffrey RB, McDougall IR, Nowels KW, Weigel RJ. Ultrasoundguided fine-needle aspiration biopsy of thyroid masses. Thyroid. 1998;8(4): 283-9.

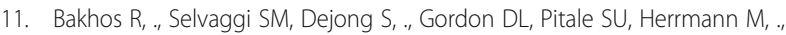
et al. Fine-needle aspiration of the thyroid: rate and causes of cytohistopathologic discordance. Diagn Cytopathol 2015;23(4):233-237.

12. Bongiovanni M, Spitale A, Faquin WC, Mazzucchelli L, Baloch ZW. The Bethesda system for reporting thyroid cytopathology: a meta-analysis. Acta Cytol. 2012;56(4):333-9.

13. Gul K, Ersoy R, Dirikoc A, Korukluoglu B, Ersoy PE, Aydin R, et al. Ultrasonographic evaluation of thyroid nodules: comparison of ultrasonographic, cytological, and histopathological findings. Endocrine. 2009;36(3):464-72

14. Lee YH, Lee NJ, Kim JH, Suh SI, Kim TK, Song JJ. Sonographically guided fine needle aspiration of thyroid nodule: discrepancies between cytologic and histopathologic findings. J Clin Ultrasound. 2008;36(1):6-11.
15. Mekel M, Gilshtein H, Al-Kurd A, Bishara B, Krausz MM, Freund HR, et al. Negative fine-needle aspiration in patients with goiter: should we doubt it? World J Surg. 2016;40(1):124-8.

16. Wu HH, Jones JN, Osman J. Fine-needle aspiration cytology of the thyroid: ten years experience in a community teaching hospital. Diagn Cytopathol. 2006;34(2):93-6.

17. Bohacek L, Milas M, Mitchell J, Siperstein A, Berber E. Diagnostic accuracy of surgeon-performed ultrasound-guided fine-needle aspiration of thyroid nodules. Ann Surg Oncol. 2012;19(1):45-51.

18. Lew Jl, Snyder RA, Sanchez YM, Solorzano CC. Fine needle aspiration of the thyroid: correlation with final histopathology in a surgical series of 797 patients. J Am Coll Surg. 2011;213(1):188-94.

19. McCoy KL, Jabbour N, Ogilvie JB, Ohori NP, Carty SE, Yim JH. The incidence of cancer and rate of false-negative cytology in thyroid nodules greater than or equal to $4 \mathrm{~cm}$ in size. Surgery. 2007;142(6):837-44 discussion 44 e13.

20. Meko JB, Norton JA. Large cystic/solid thyroid nodules: a potential falsenegative fine-needle aspiration. Surgery. 1995;118(6):996-1003 discussion -4 .

21. Richmond BK, Rudy J, Benny C, Adam U, Zachary AR, William M, et al. Falsenegative results with the Bethesda system of reporting thyroid cytopathology: predictors of malignancy in thyroid nodules classified as benign by cytopathologic evaluation. Am Surg. 2014;80(8):811-6.

22. Yeh MW, Demircan $\mathrm{O}$, Ituarte $\mathrm{P}$, Clark $\mathrm{OH}$. False-negative fine-needle aspiration cytology results delay treatment and adversely affect outcome in patients with thyroid carcinoma. Thyroid. 2004;14(3):207-15.

23. Lloyd RV, Osamura RY, Kloppel G, Rosai J. WHO classification of tumours: pathology and genetics of tumours of endocrine organs. 4th ed. Lyon: IARC 2017.

24. Mehanna R, Murphy M, McCarthy J, O'Leary G, Tuthill A, Murphy MS, et al. False negatives in thyroid cytology: impact of large nodule size and follicular variant of papillary carcinoma. Laryngoscope. 2013;123(5):1305-9.

25. Raab SS, Grzybicki DM, Sudilovsky D, Balassanian R, Janosky JE, Vrbin CM. Effectiveness of Toyota process redesign in reducing thyroid gland fineneedle aspiration error. Am J Clin Pathol. 2006;126(4):585-92.

26. Giles WH, Maclellan RA, Gawande AA, Ruan DT, Alexander EK, Moore FD Jr, et al. False negative cytology in large thyroid nodules. Ann Surg Oncol. 2015:22(1):152-7.

27. Pinchot SN, Hatem AW, Sarah S, Rebecca S, Herbert C. Accuracy of fineneedle aspiration biopsy for predicting neoplasm or carcinoma in thyroid nodules $4 \mathrm{~cm}$ or larger. Arch Surg. 2009;144(7):649-55.

28. Ylagan $L R$, Farkas $T$, Dehner LP. Fine needle aspiration of the thyroid: a cytohistologic correlation and study of discrepant cases. Thyroid. 2004;14(1): $35-41$.

29. Yu XM, Patel PN, Chen H, Sippel RS. False-negative fine-needle aspiration of thyroid nodules cannot be attributed to sampling error alone. Am J Surg. 2012:203(3):331-4 discussion 4

30. Campbell MJ, Seib CD, Candell L, Gosnell JE, Duh QY, Clark OH, et al. The underestimated risk of cancer in patients with multinodular goiters after a benign fine needle aspiration. World J Surg. 2015;39(3):695-700.

31. McHenry CR, Huh ES, Machekano RN. Is nodule size an independent predictor of thyroid malignancy? Surgery. 2008;144(6):1062-8 discussion 8-9.

32. Siddiqui MA, Griffith KA, Michael CW, Pu RT. Nodule heterogeneity as shown by size differences between the targeted nodule and the tumor in thyroidectomy specimen: a cause for a false-negative diagnosis of papillary thyroid carcinoma on fine-needle aspiration. Cancer. 2008;114(1): 27-33.

33. Smith JJ, Chen X, Schneider DF, Broome JT, Sippel RS, Chen H, et al. Cancer after thyroidectomy: a multi-institutional experience with 1,523 patients. J Am Coll Surg. 2013;216(4):571-7 discussion 7-9.

34. Porterfield JR Jr, Grant CS, Dean DS, Thompson GB, Farley DR, Richards ML, et al. Reliability of benign fine needle aspiration cytology of large thyroid nodules. Surgery. 2008;144(6):963-8 discussion 8-9.

35. Shrestha M, Crothers BA, Burch HB. The impact of thyroid nodule size on the risk of malignancy and accuracy of fine-needle aspiration: a 10-year study from a single institution. Thyroid. 2012;22(12):1251-6.

36. Luo J, McManus $\mathrm{C}$, Chen $\mathrm{H}$, Sippel RS. Are there predictors of malignancy in patients with multinodular goiter? J Surg Res. 2012;174(2):207-10.

37. Rios A, Rodriguez JM, Galindo PJ, Montoya M, Tebar FJ, Sola J, et al. Utility of fine-needle aspiration for diagnosis of carcinoma associated with multinodular goitre. Clin Endocrinol. 2004;61(6):732-7. 
38. Baloch ZW, Fleisher S, LiVolsi VA, Gupta PK. Diagnosis of "follicular neoplasm": a gray zone in thyroid fine-needle aspiration cytology. Diagn Cytopathol. 2002;26(1):41-4.

39. Faquin WC. Diagnosis and reporting of follicular-patterned thyroid lesions by fine needle aspiration. Head Neck Pathol. 2009;3(1):82-5.

40. Gallagher J, Oertel YC, Oertel JE. Follicular variant of papillary carcinoma of the thyroid: fine-needle aspirates with histologic correlation. Diagn Cytopathol. 1997;16(3):207-13.

41. Sangalli G, Serio G, Zampatti C, Bellotti M, Lomuscio G. Fine needle aspiration cytology of the thyroid: a comparison of 5469 cytological and final histological diagnoses. Cytopathology. 2010;17(5):245-50.

42. Pusztaszeri MP, Krane JF, Cibas ES, Daniels G, Faquin WC. FNAB of benign thyroid nodules with papillary hyperplasia: a cytological and histological evaluation. Cancer Cytopathol. 2014;122(9):666-77.

43. Baloch ZW, LiVolsi VA. Current role and value of fine-needle aspiration in nodular goitre. Best Pract Res Clin Endocrinol Metab. 2014;28(4):531-44.

44. Baloch ZW, LiVolsi VA. Cytologic and architectural mimics of papillary thyroid carcinoma. Diagnostic challenges in fine-needle aspiration and surgical pathology specimens. Am J Clin Pathol. 2006;125(Suppl):S135-44.

45. Mahajan A, Lin X, Nayar R. Thyroid Bethesda reporting category, 'suspicious for papillary thyroid carcinoma', pitfalls and clues to optimize the use of this category. Cytopathology. 2013;24(2):85-91.

46. Mai KT, Landry DC, Thomas J, Burns BF, Commons AS, Yazdi HM, et al. Follicular adenoma with papillary architecture: a lesion mimicking papillary thyroid carcinoma. Histopathology. 2001;39(1):25-32.

47. Powari $\mathrm{M}$, ., John A, St Jones $\mathrm{H}$. Are all thyroid papillae malignant? An unusual pitfall in FNAC. Cytopathology Official Journal of the British Society for Clinical Cytology 2010;18(2):120-2.

48. Faquin WC. The thyroid gland: recurring problems in histologic and cytologic evaluation. Arch Pathol Lab Med. 2008;132(4):622-32.

49. Faser CR, Marley EF, Oertel YC. Papillary tissue fragments as a diagnostic pitfall in fine-needle aspirations of thyroid nodules. Diagn Cytopathol. 1997; 16(5):454-9.

50. Junik R, Juraniec O, Pypkowski J, Krymer A, Marszalek A. A difficult diagnosis: a case report of combined Riedel's disease and fibrosing Hashimoto's thyroiditis. Endokrynol Pol. 2011;62(4):351-6.

51. Kollur SM, El Sayed S, El Hag IA. Follicular thyroid lesions coexisting with Hashimoto's thyroiditis: incidence and possible sources of diagnostic errors. Diagn Cytopathol. 2003;28(1):35-8.

52. Macdonald L, Yazdi HM. Fine needle aspiration biopsy of Hashimoto's thyroiditis - sources of diagnostic error. Acta Cytol. 1999;43(3):400-6.

53. Harvey AM, Truong LD, Mody DR. Diagnostic pitfalls of Hashimoto's/ lymphocytic thyroiditis on fine-needle aspirations and strategies to avoid overdiagnosis. Acta Cytol. 2012;56(4):352-60

54. Yi Kl, Ahn S, Park DY, Lee JC, Lee BJ, Wang SG, et al. False-positive cytopathology results for papillary thyroid carcinoma: a trap for thyroid surgeons. Clin Otolaryngol. 2017;42(6):1153-60.

55. Baloch ZW, Livolsi VA. Diagnostic dilemmas in thyroid pathology: follicular variant of papillary thyroid carcinoma and classic papillary thyroid carcinoma arising in lymphocytic thyroiditis. Ajsp Reviews \& Reports. 2003; 8(1):47-56.

56. Garcia Solano J, Gimenez Bascunana A, Sola Perez J, Campos Fernandez J, Martinez Parra D, Sanchez Sanchez C, et al. Fine-needle aspiration of subacute granulomatous thyroiditis (De Quervain's thyroiditis): a clinicocytologic review of 36 cases. Diagn Cytopathol. 1997;16(3):214-20.

57. Hoang TD, Mai VQ, Clyde PW, Shakir MK. Simultaneous occurrence of subacute thyroiditis and Graves' disease. Thyroid. 2011;21(12):1397-400.

58. Shabb NS, Tawil A, Gergeos F, Saleh M, Azar S. Multinucleated giant cells in fine-needle aspiration of thyroid nodules: their diagnostic significance. Diagn Cytopathol. 1999;21(5):307-12.

59. Al-Ashaa Y, Hefny AF, Joshi S, Abu-Zidan FM. Papillary thyroid carcinoma presenting as a lateral neck cyst. Afr Health Sci. 2011;11(2):296-300.

60. Fadda G, Mulè A, Rufini V, Ardito G, Revelli L, Fiorino MC, et al. Cystic medullary thyroid carcinoma: report of a case with morphological and clinical correlations. Endocr Pathol. 2000;11(4):373-7.

61. Faquin WC, Cibas ES, Renshaw AA. "atypical" cells in fine-needle aspiration biopsy specimens of benign thyroid cysts. Cancer. 2005;105(2):71-9.

62. Jaffar R, Mohanty SK, Khan A, Fischer AH. Hemosiderin laden macrophages and hemosiderin within follicular cells distinguish benign follicular lesions from follicular neoplasms. Cytojournal. 2009;6:3.
63. Renshaw AA. "Histiocytoid" cells in fine-needle aspirations of papillary carcinoma of the thyroid: frequency and significance of an underrecognized cytologic pattern. Cancer. 2002;96(4):240-3.

64. Bongiovanni M, Papadakis GE, Rouiller N, Marino L, Lamine F, Bisig B, et al. The Bethesda system for reporting thyroid cytopathology explained for practitioners: frequently asked questions. Thyroid. 2018;28(5):556-65.

\section{Publisher's Note}

Springer Nature remains neutral with regard to jurisdictional claims in published maps and institutional affiliations.
Ready to submit your research? Choose BMC and benefit from:

- fast, convenient online submission

- thorough peer review by experienced researchers in your field

- rapid publication on acceptance

- support for research data, including large and complex data types

- gold Open Access which fosters wider collaboration and increased citations

- maximum visibility for your research: over $100 \mathrm{M}$ website views per year

At BMC, research is always in progress.

Learn more biomedcentral.com/submissions 